\title{
Analysis of the selectivity filter of the voltage-gated sodium channel $\mathrm{Na}_{\mathrm{v}} \mathrm{Rh}$
}

Xu Zhang ${ }^{1,2,3, *}$, Mengdie Xia ${ }^{2,4, *}$, Yang $\mathrm{Li}^{2,4,{ }^{*}}$, Huihui $\mathrm{Liu}^{2,4,{ }^{*}}$, Xin Jiang ${ }^{1,2,3}$, Wenlin Ren ${ }^{1,2,3}$, Jianping Wu ${ }^{1,2,3}$, Paul DeCaen ${ }^{5}$, Feng Yu ${ }^{6}$, Sheng Huang ${ }^{6}$, Jianhua $\mathrm{He}^{6}$, David E Clapham ${ }^{5}$, Nieng Yan ${ }^{1,2,3}$, Haipeng Gong

${ }^{I}$ State Key Laboratory of Bio-membrane and Membrane Biotechnology, Tsinghua University, Beijing 100084, China; ${ }^{2}$ Center for Structural Biology, School of Life Sciences and School of Medicine, Tsinghua University, Beijing 100084, China; ${ }^{3}$ TsinghuaPeking Center for Life Sciences, Tsinghua University, Beijing 100084, China; ${ }^{4}$ MOE Key Laboratory of Bioinformatics, Tsinghua University, Beijing 100084, China; ${ }^{5}$ Howard Hughes Medical Institute, Department of Cardiology, Children's Hospital Boston, Department of Neurobiology, Harvard Medical School, Boston, MA 02115, USA; ${ }^{6}$ Shanghai Institute of Applied Physics, Chinese Academy of Sciences, 239 Zhangheng Road, Shanghai 201204, China

$\mathrm{NaChBac}$ is a bacterial voltage-gated sodium $\left(\mathrm{Na}_{v}\right)$ channel that shows sequence similarity to voltage-gated calcium channels. To understand the ion-permeation mechanism of $\mathrm{Na}_{\mathrm{v}}$ channels, we combined molecular dynamics simulation, structural biology and electrophysiological approaches to investigate the recently determined structure of $\mathrm{Na}_{v} \mathrm{Rh}$, a marine bacterial $\mathrm{NaChBac}$ ortholog. Two $\mathrm{Na}^{+}$binding sites are identified in the selectivity filter (SF) in our simulations: The extracellular $\mathrm{Na}^{+}$ion first approaches site 1 constituted by the side groups of Ser181 and Glu183, and then spontaneously arrives at the energetically more favorable site 2 formed by the carbonyl oxygens of Leu179 and Thr178. In contrast, $\mathrm{Ca}^{2+}$ ions are prone to being trapped by Glu183 at site 1, which then blocks the entrance of both $\mathrm{Na}^{+}$and $\mathrm{Ca}^{2+}$ to the vestibule of the $\mathrm{SF}$. In addition, $\mathrm{Na}^{+}$permeates through the selective filter in an asymmetrical manner, a feature that resembles that of the mammalian $\mathrm{Na}_{\mathrm{v}}$ orthologs. The study reported here provides insights into the mechanism of ion selectivity on $\mathrm{Na}^{+}$over $\mathrm{Ca}^{2+}$ in mammalian $\mathrm{Na}_{\mathrm{v}}$ channels.

Keywords: voltage-gated ion channels; $\mathrm{Na}_{\mathrm{v}}$ channels; $\mathrm{NaChBac}$; ion selectivity; permeation mechanism; structural asymmetry Cell Research (2013) 23:409-422. doi:10.1038/cr.2012.173; published online 18 December 2012

\section{Introduction}

Voltage-gated sodium $\left(\mathrm{Na}_{\mathrm{v}}\right)$ channels are responsible for the rising phase of action potential in neurons and other excitable cells $[1,2] . \mathrm{Na}_{\mathrm{v}}$ channels consist of a large pore-forming $\alpha$ subunit and auxiliary subunits. The $\alpha$ subunit contains four homologous domains (DI-DIV) [3] linearly connected in a single polypeptide chain. Each domain is comprised of six transmembrane segments (S1-S6). The pore domain formed by the S5 and S6 segments from the four repeats provides structural support for the selectivity filter (SF) that determines the ion selectivity [3]. The S1-S4 segments in each repeat con-

*These four authors contributed equally to this work. Correspondence: Haipeng Gong

E-mail: hgong@tsinghua.edu.cn

Received 28 August 2012; revised 14 October 2012; accepted 16 November 2012; published online 18 December 2012 stitute a relative mobile voltage-sensing domain (VSD) that regulates the channel opening upon depolarization of membrane potentials [4-7]. VSDs are connected to the pore domain through connecting helices S4-5. Studies of $\mathrm{K}_{\mathrm{v}}$ channels suggested that the voltage-dependent conformational changes of VSDs, particularly of the gating charge-containing S4 segments, lead to the opening of the cytoplasmic gate of the pore domain $[5,6,8]$.

Most voltage-gated channels selectively distinguish ions with similar charges and radii [9]. The ion selectivity of potassium channels has been rigorously studied, particularly since the determination of the first $\mathrm{K}^{+}$channel structure KcsA, which contains a $12 \AA$-long, narrow and rigid pore lined with carbonyl oxygen atoms from the P-loops of four identical subunits [10]. The pore of KcsA only permits the passage of dehydrated potassium ions $[10,11]$. This property is highly conserved in most types of potassium channels [4-6, 12-17]. The ion permeation, however, is different in $\mathrm{Na}_{\mathrm{v}}$ channels where $\mathrm{Na}^{+}$is 
predicted to pass through the SF vestibule in a hydrated or partially dehydrated state according to the dimension of the permeation pathway [18-21]. In mammalian $\mathrm{Na}_{\mathrm{v}}$ channels, the negatively charged vestibule of the SF has two rings of charged residues [3]. The outer ring of the $\mathrm{SF}$, consisting of four acidic residues (EEDD or EEMD), determines the ion permeation rate, but plays negligible roles in selectivity [22]. The inner ring of the SF, corresponding to conserved residues DEKA from DI-DIV, respectively, plays a more prominent role in ion selection. Mutations of these key residues exhibit pronounced influence on the $\mathrm{Na}^{+}$selectivity and tetrodotoxin/saxitoxin binding affinity. Among the four key residues, Lys is indispensable for exclusion of $\mathrm{Ca}^{2+}$ permeation and for discrimination between $\mathrm{Na}^{+}$and $\mathrm{K}^{+}$[23-27]. Mutating DEKA to EEEE transforms the $\mathrm{Na}_{\mathrm{v}}$ channel into a $\mathrm{Ca}^{2+}-$ selective channel [28].

Despite the high sequence similarity to voltage-gated calcium $\left(\mathrm{Ca}_{\mathrm{v}}\right)$ channels, $\mathrm{Na}_{\mathrm{v}}$ channels selectively discriminate the two physiologically essential cations $\left(\mathrm{Na}^{+}\right.$ and $\mathrm{Ca}^{2+}$ ), both of which are abundant in the extracellular milieus. In addition, $\mathrm{Ca}^{2+}$ blocks the $\mathrm{Na}_{\mathrm{v}}$ channel in a voltage-dependent manner, and accelerates the closing of its activation gate. In physiological conditions, extracellular $\mathrm{Ca}^{2+}$ reduces the apparent $\mathrm{Na}^{+}$conductance by $20 \%-40 \%$ at the resting potential [29-31]. Likewise, cytosolic $\mathrm{Ca}^{2+}$ also weakens $\mathrm{Na}^{+}$conductance through the $\mathrm{Na}_{\mathrm{v}}$ channel $[32,33]$. Despite rigorous functional characterizations, the mechanism of $\mathrm{Na}_{\mathrm{v}}$ channel selectivity remains elusive at the structural level.

The prokaryotic $\mathrm{NaChBac}$ provides a good model for structural elucidation and functional characterizations of $\mathrm{Na}_{\mathrm{v}}$ channels. Unlike the eukaryotic counterparts, $\mathrm{NaCh}-$ $\mathrm{Bac}$ is a homo-tetramer, with each monomer composed of six transmembrane segments [34]. Replacement of specific residues in the SF alters the ion preference from $\mathrm{Na}^{+}$to $\mathrm{Ca}^{2+}$ [35]. The recent crystal structures of two $\mathrm{NaChBac}$ homologs, $\mathrm{Na}_{v} \mathrm{Ab}$ [36] and $\mathrm{Na}_{v} \mathrm{Rh}$ [37], have provided novel insights into the mechanism of $\mathrm{Na}^{+}$selectivity at a structural level. Based on the structure of $\mathrm{Na}_{\mathrm{v}} \mathrm{Ab}$, several independent groups explored the permeation of $\mathrm{Na}^{+}$and $\mathrm{K}^{+}$, but not $\mathrm{Ca}^{2+}$, using computer simulation $[20,21,38,39]$. Notably, a $\mathrm{Ca}^{2+}$ ion is bound to the $\mathrm{SF}$ in the crystal structure of $\mathrm{Na}_{\mathrm{v}} \mathrm{Rh}$, while functional study demonstrated that $\mathrm{Ca}^{2+}$ blocks $\mathrm{Na}^{+}$permeation through the $\mathrm{SF}$ of $\mathrm{Na}_{\mathrm{v}} \mathrm{Rh}$ [37]. Dudev et al. systematically discussed the ion selectivity of $\mathrm{Na}^{+} / \mathrm{K}^{+}$and $\mathrm{Na}^{+} / \mathrm{Ca}^{2+}$ in two reports $[40,41]$. Their studies, however, were based on reduced molecular models of the constriction site in the absence of crystal structures. Here, we employed the atomic structure of the pore domain of the recently reported $\mathrm{Na}_{\mathrm{v}} \mathrm{Rh}$, and combined molecular dynamics (MD) simulations as well as structural and electrophysiological analysis to investigate the mechanism by which $\mathrm{Na}_{\mathrm{v}} \mathrm{Rh}$ preferentially selects $\mathrm{Na}^{+}$over $\mathrm{Ca}^{2+}$.

\section{Results}

$\mathrm{Na}^{+}$permeates across $\mathrm{SF}$ through two successive binding sites in $\mathrm{Na}_{v} \mathrm{Rh}$

Unlike the organization of a dimer of dimer in $\mathrm{Na}_{\mathrm{v}} \mathrm{Ab}$, $\mathrm{Na}_{\mathrm{v}} \mathrm{Rh}$ exists as an asymmetric tetramer despite the identical primary sequence in each protomer [37]. As seen in the crystal structure of $\mathrm{Na}_{\mathrm{v}} \mathrm{Rh}$, the side chains of Ser180, Ser181 and Glu183, as well as the carbonyl oxygen atoms provided by Thr178 and Leu179, constitute the SF of $\mathrm{Na}_{v} \mathrm{Rh}$ (Figure 1A). The four acidic residues Glu183 of $\mathrm{Na}_{\mathrm{v}} \mathrm{Rh}$ correspond to the outer ring of negative charges in mammalian $\mathrm{Na}_{\mathrm{v}}$ channels. The polar residues Ser180, equivalent to DEKA in the inner ring of mammalian channels, form the constriction site in the SF (Figure 1B). Ser181, as well as Tyr407 in Domain I of $\mathrm{hNa}_{\mathrm{v}} 1.4$ (highlighted in yellow in Figure 1B), may provide hydroxyl group as a hydrogen bond donor, which will be further discussed in later session.

To examine the ion permeation process through the sodium channel, we performed MD simulations. The pore domain of $\mathrm{Na}_{\mathrm{v}} \mathrm{Rh}$ (residues from Glu118 to Leu228) was inserted into a POPC lipid bilayer. The system was simulated in $70 \mathrm{mM} \mathrm{NaCl}$ solution (simulation 1 and 2 in Supplementary information, Table S1 and Movie S1). In the simulation, the collapsed SF in the inactivated crystal structure of $\mathrm{Na}_{\mathrm{v}} \mathrm{Rh}$ opened spontaneously (Supplementary information, Figure S1A and S1B). The structural opening is primarily caused by the quick re-orientation of the side chains of Ser181 in the four protomers, rather than by the movement of backbone atoms (Supplementary information, Figures S1C, S1D and S2). After the opening of SF in the simulation, a $\mathrm{Na}^{+}$ion in the extracellular bulk solution moved close to the periplasmic entrance of SF (site 1 in Figure 1C) and remained there for $\sim 3 \mathrm{~ns}$ by favorably interacting with the side chain oxygens of Glu183 or Ser181. The ion then left site 1, slipped more deeply into SF and lingered around the second binding site (site 2 in Figure 1C, approximately coincident with the $\mathrm{Ca}^{2+}$ binding site in the $\mathrm{Na}_{\mathrm{v}} \mathrm{Rh}$ crystal structure), where it was caged by eight carbonyl oxygen atoms from Thr178 and Leu179 in all four protomers. The vacant site 1 was then occupied by another $\mathrm{Na}^{+}$. Finally, both sites were occupied by ions in most of the remaining trajectory (Figure 1C). The two ion-binding sites observed here in $\mathrm{Na}_{v} \mathrm{Rh}$ are not identical to the ones in $\mathrm{Na}_{\mathrm{v}} \mathrm{Ab}$ defined in previous studies $[20,21,38,39]$, owing to the altered amino-acid sequences in the SF of the two proteins (Fig- 
A

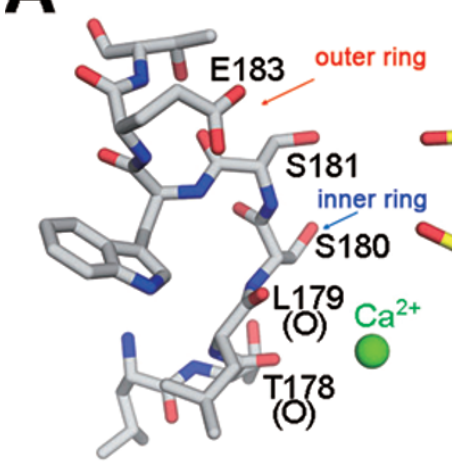

B

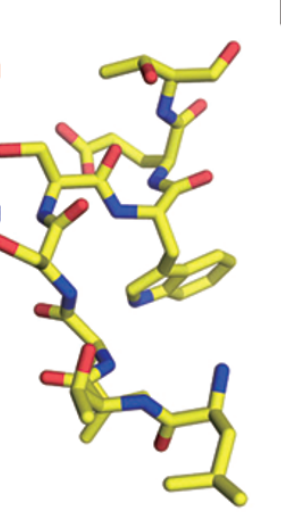

$\mathrm{Na} \mathrm{Rh}$

$\mathrm{NaAb}$

$\mathrm{hNa}$. 1.4I

$\mathrm{hNa}$ 1.4II

$\mathrm{hNa}$ 1.4III

$\mathrm{hNa}$ 1.4IV

$\mathrm{hCa}_{\mathrm{v}} 1.3 \mathrm{I}$

$\mathrm{hCa}_{\mathrm{v}} 1.3 \mathrm{II}$

hCa 1.3 III

hCa $1.3 \mathrm{IV}$

$\mathrm{NaChBac}$

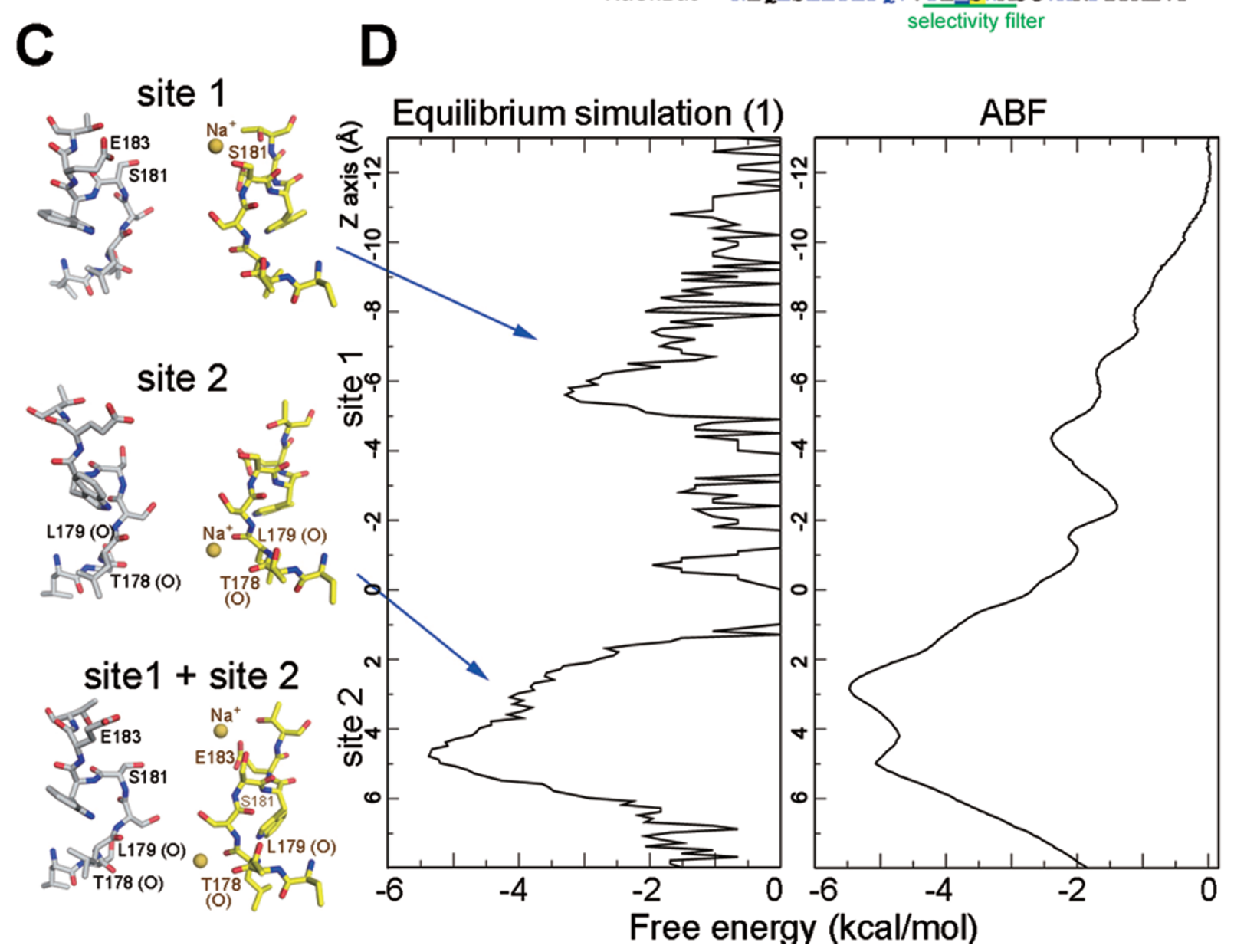

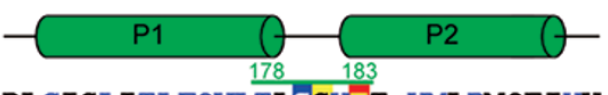

DLGISLITLFQVLTLSSWET-VMLPMQEIYW TLGESFYTLFQVMTLESWSMGIVRPLMEVYP TFSWAFLALFRLMTQDYWEN-LFQLTLRAAG DFFHSFLIVFRILCGW-WI -TMWDCME--NVGLGYLSLLQVAT FKGWMD-IMYAAVDSRE: TFGNSIICLFEITTSAGWDG-LLNPILNSGP NFAFAMLTVFQCITMEGWTD-VLYWMNDAMG NFPQALLTVFQILTGEDWNA-VMYDGIMAYG NVLSAMMALFTVSTFEGWPA-LLYKAIDSNG: TFPQAVLLLFRCATGEAWQE-IMIACLPGKL NLQLSLLTLFQVVTLESWASGVMRPI FAEVP selectivity filter

Figure 1 The SF of $\mathrm{Na}_{\mathrm{v}} \mathrm{Rh}$ contains two $\mathrm{Na}^{+}$binding sites. (A) The structure of the $\mathrm{Na}_{\mathrm{v}} \mathrm{Rh}$ SF (PDB code: 4DXW). The SF vestibule is constituted by the side groups of Ser180/Ser181/Glu183, and carbonyl oxygen atoms of Thr178 and Leu179. $\mathrm{A} \mathrm{Ca}^{2+}$ ion is bound at an inner site of SF. For visual clarity, only two diagonal protomers are shown. (B) The SF sequence of $\mathrm{Na}_{v} \mathrm{Rh}$ is similar to those of the eukaryotic $\mathrm{Na}_{v}$ channels. Sequences of $\mathrm{Na}_{v} \mathrm{Rh}, \mathrm{Na}_{\mathrm{v}} \mathrm{Ab}, \mathrm{NaChBac}$ and human $\mathrm{Na}_{\mathrm{v}} 1.4$ and $\mathrm{Ca}_{\mathrm{v}} 1.3$ were aligned using ClustalW. The residues in the negatively charged outer and inner rings are shaded red and blue, respectively. Ser181 in $\mathrm{Na}_{\mathrm{v}} \mathrm{Rh}$ and its corresponding residues in other homologs including Tyr407 in $\mathrm{hNa} v 1.4 \mathrm{I}$ are shaded yellow. (C) The simulated structures of SF when $\mathrm{Na}^{+}$binds to site 1 (upper panel), site 2 (middle panel) or both (lower panel). The snapshots are taken from simulation 1 in Supplementary information, Table S1. $\mathrm{Na}^{+}$ions are shown as brown spheres. Arrows indicate the corresponding positions of SF structures in free energy profile. (D) Left panel, the free energy estimated from the negative logarithm of $\mathrm{Na}^{+}$density in the MD simulation of $\mathrm{Na}_{\mathrm{v}} \mathrm{Rh}$ pore domain as a function of the axial position of SF, derived from simulation 1. Right panel, the single ion PMF of $\mathrm{Na}^{+}$as a function of the SF axis. All structure figures were prepared with PyMol [64]. 
ure 1B). Notably, the residues at the outer ring and the constriction site (inner layer) are swapped in $\mathrm{Na}_{\mathrm{v}} \mathrm{Ab}$ and $\mathrm{Na}_{\mathrm{v}} \mathrm{Rh}$. The outer ring of the SF in $\mathrm{Na}_{\mathrm{v}} \mathrm{Ab}$ (corresponding to site 1 in $\mathrm{Na}_{v} \mathrm{Rh}$ ) is composed of Serine instead of the negatively charged Glutamic acid, while the constriction site (corresponding to Ser180 in $\mathrm{Na}_{\mathrm{v}} \mathrm{Rh}$ ) is formed by four Glu residues. Therefore, the most extracellular ion-binding site in $\mathrm{Na}_{\mathrm{v}} \mathrm{Ab}$ was identified to be around the constriction point, termed as site $_{\mathrm{HFS}}$, in all previous simulation studies. In contrast, the same site in $\mathrm{Na}_{\mathrm{v}} \mathrm{Rh}$ becomes a high-energy transition state (as shown below in the free energy calculation in Figure 1D) and can no longer favorably bind cations.

To examine the preferential $\mathrm{Na}^{+}$ion binding at both sites, the residence probability of $\mathrm{Na}^{+}\left(P_{\mathrm{Na}}\right)$ along the permeation pathway is calculated from the trajectory. The probability is further transformed by negative logarithm $\left(\mathrm{G}=-\mathrm{RT} \log \left(P_{\mathrm{Na}}\right)\right)$ for convenient comparison with the free energy calculation described below (Figure 1D, left panel and Supplementary information, Figure S3). For more detailed thermodynamics analysis, the free energy profile for ion diffusion along the pathway was generated by the adaptive biasing force (ABF) method [42-45]. The potential of mean force (PMF) curve also indicates two energetically favorable binding sites (Figure 1D, right panel), the positions of which agree perfectly with sites 1 and 2 derived from equilibrium simulation. Furthermore, both the stronger binding affinity at site 2 over site 1 and the relatively low free energy barrier $(\sim 1.01 \mathrm{kcal} / \mathrm{mol})$ between the two sites explains the spontaneous and rapid transition of $\mathrm{Na}^{+}$ion from site 1 to site 2, as described above. This spontaneous transition was also observed by Qiu et al. [39] in their simulation on $\mathrm{Na}_{\mathrm{v}} \mathrm{Ab}$. In other simulations on $\mathrm{Na}_{\mathrm{v}} \mathrm{Ab}$, the extracellular sites were, however, evaluated to be more favorably occupied than the intracellular sites, thus precluding the natural flow of $\mathrm{Na}^{+}$ from the extracellular site to the inner one in the absence of the electrochemical gradient $[20,21]$.

After the first $\mathrm{Na}^{+}$ion naturally transits from site 1 to site 2 , the vacant site 1 is quickly occupied by another $\mathrm{Na}^{+}$, and electrostatic repulsion from the incoming $\mathrm{Na}^{+}$ ion may partially destabilize the binding of the first ion at site 2 and will facilitate its ongoing movement toward cytoplasm. To test this idea, the binding affinity of $\mathrm{Na}^{+}$at site 2 was calculated by free energy perturbation (FEP) $[46,47]$ in both the presence and the absence of another $\mathrm{Na}^{+}$bound at site 1 . As shown in Supplementary information, Table S3, the binding affinity is $3.675 \pm 0.128$ $\mathrm{kcal} / \mathrm{mol}$ when site 1 is vacant. In contrast, the affinity is weakened to $2.567 \pm 0.142 \mathrm{kcal} / \mathrm{mol}$ when an incoming $\mathrm{Na}^{+}$occupies site 1 . This $1.11 \pm 0.19 \mathrm{kcal} / \mathrm{mol}$ reduction in binding affinity, therefore, facilitates the ongoing per- meation of the ion bound at site 2. In an independently repeated FEP calculation, the reduction in binding affinity is $1.03 \pm 0.19 \mathrm{kcal} / \mathrm{mol}$, which is close to the above value. Unfortunately, the continuous $\mathrm{Na}^{+}$current cannot be directly observed in the equilibrium simulation since the activation gate is closed in the crystal structure used in this simulation. The above two-ion moving behavior is different from the knock-on mechanism [48] in the potassium channel, in which two $\mathrm{K}^{+}$ions bind simultaneously and jump together to switch between S2:S4 and $\mathrm{S} 1$ :S3 binding patterns upon the incoming ions due to the presence of four binding sites. On the contrary, the two bound ions in sodium channels are less coupled. They can occupy the two binding sites either alone or simultaneously. Similar "weakly coupled knock-on" behaviors in $\mathrm{Na}^{+}$conduction were described by previous simulations on $\mathrm{Na}_{\mathrm{v}} \mathrm{Ab}[20,21]$.

\section{$\mathrm{Ca}^{2+}$ binding at site 1 precludes $\mathrm{Na}^{+}$permeation from the extracellular side}

Our previous research showed that not only is $\mathrm{Ca}^{2+}$ incapable of passing through $\mathrm{SF}$ of $\mathrm{Na}_{\mathrm{v}} \mathrm{Rh}$ under physiological condition, but it also blocks the $\mathrm{Na}^{+}$conductance when applied at high concentrations from the extracellular side [37]. The same phenomenon is observed in a series of MD simulations conducted at $70 \mathrm{mM}, 200 \mathrm{mM}$ and $400 \mathrm{mM} \mathrm{CaCl}_{2}$ (simulation 3a, 3b, 4, 5, 6a and $6 \mathrm{~b}$ in Supplementary information, Table S1 and Movie S2). In all six simulations, the $\mathrm{Ca}^{2+}$ quickly occupies site 1 and favorably binds with the negatively charged side groups of Glu183. High $\mathrm{CaCl}_{2}(400 \mathrm{mM})$ concentration accelerates the initial arrival of $\mathrm{Ca}^{2+}$ at site 1 (Supplementary information, Figure S4). Furthermore, in five of the six simulations (simulation $3 \mathrm{a}$ and $3 \mathrm{~b}$ for $70 \mathrm{mM} \mathrm{CaCl}_{2}$, simulation 4 for $200 \mathrm{mM} \mathrm{CaCl}_{2}$, simulation $6 \mathrm{a}$ and $6 \mathrm{~b}$ for $\left.400 \mathrm{mM} \mathrm{CaCl}_{2}\right), \mathrm{Ca}^{2+}$ never permeates along the pathway into site 2. Only in one rare case (simulation 5 for $200 \mathrm{mM} \mathrm{CaCl}_{2}$ in Supplementary information, Table S1) could $\mathrm{Ca}^{2+}$ squeeze into the vestibule of SF and approach site 2 (Supplementary information, Movie S3). Once the $\mathrm{Ca}^{2+}$ leaves for site 2, site 1 is instantly occupied by another $\mathrm{Ca}^{2+}$ from the extracellular solution. Apparently, the $\mathrm{Ca}^{2+}$ ion penetration did not strictly follow a concentration-dependent manner. This is possibly caused by the low probability of the event and the random factors in MD simulation.

Interestingly, the binding positions of $\mathrm{Na}^{+}$and $\mathrm{Ca}^{2+}$ at site 1 differ slightly: $\mathrm{Ca}^{2+}$ binds at a location closer to the periplasm than $\mathrm{Na}^{+}$(Figure 2A). This difference is caused by their distinct interaction manners with residues at the entrance to SF. Both $\mathrm{Na}^{+}$and $\mathrm{Ca}^{2+}$ lose one or two closely coordinated water molecules to intimately 
interact with the channel (Figure 2B and Supplementary information, Figures S5A, S6A and S6C), similar to the observations in previous simulations on $\mathrm{Na}_{\mathrm{v}} \mathrm{Ab}[20$, 21]. $\mathrm{Na}^{+}$prefers interacting with the hydroxyl group of Ser181 in one protomer, and sometimes with Glu183 from an adjacent protomer. In contrast, $\mathrm{Ca}^{2+}$ only favorably coordinates with the carboxyl group of Glu183, a group more electronegative than the hydroxyl group of Ser181 (Figure 2C and 2D; Supplementary information, Figure S5B). Similarly, in the plane perpendicular to the permeation pathway, $\mathrm{Ca}^{2+}$ usually diffuses farther off the central axis $(\sim 6 \AA)$ than $\mathrm{Na}^{+}(\sim 4 \AA)$ to better interact with the carboxyl group of Glu183 (Figure 2D and 2E). The free energy profile of $\mathrm{Ca}^{2+}$ along the permeation pathway (Figure 2F) also shows a marked energy minimum near site 1 , with a binding affinity much stronger than $\mathrm{Na}^{+}$. Although favorable binding is also predicted at site 2, the free energy barrier between the two sites $(\sim 11.38 \mathrm{kcal} /$ mol) is high enough to prevent most permeation events, agreeing with the observation in the equilibrium simulations. This barrier can be overcome by a sufficient concentration difference of $\mathrm{Ca}^{2+}$ between the periplasm and the central cavity.

The free energy profile appears to contradict with the crystal structure of $\mathrm{Na}_{v} \mathrm{Rh}$, in which a $\mathrm{Ca}^{2+}$ ion is identified at a location coincident with site 2 . No bound ion, however, was detected at the more favorable site 1 . This contradiction can be reconciled by considering the sparse spatial distribution of the four carboxyl groups within site 1 . After approaching site 1 , the $\mathrm{Ca}^{2+}$ randomly selects a carboxyl group to bind, and further binding of $\mathrm{Ca}^{2+}$ to other carboxyl groups is prohibited by electrostatic repulsion. The random positioning of $\mathrm{Ca}^{2+}$ among the four distantly located carboxyl groups raises structural heterogeneity, which may finally result in the underrepresentation of the electron density of $\mathrm{Ca}^{2+}$ bound at site 1 .

When both $\mathrm{Ca}^{2+}$ and $\mathrm{Na}^{+}$exist in the solution, they compete for binding to site $1 . \mathrm{Ca}^{2+}$ takes advantage in the competition because of its more extracellular location as well as the more favorable binding affinity. Once this site is occupied by a $\mathrm{Ca}^{2+}$ ion, electrostatic repulsion generally prevents the approximation of $\mathrm{Na}^{+}$(simulation 7 and 10 in Supplementary information, Table S1 and Movie S4). In simulation, $\mathrm{Na}^{+}$can never reach its most favorable binding site (close to Ser181) in the presence of $\mathrm{Ca}^{2+}$. It stays more distantly away from the central axis to coordinate with both carboxylate group of Glu183 and the hydroxyl oxygen of Ser181, opposite to the bound $\mathrm{Ca}^{2+}$ (Figure 2B, 2C and bottom right panel of 2D). The electrostatic repulsion between cations is partially alleviated by this way. The above observation decently explains the experimental observations that millimolar $\mathrm{Ca}^{2+}$ ions block the $\mathrm{Na}^{+}$current through $\mathrm{Na}_{\mathrm{v}} \mathrm{Rh}$ from the extracellular side [37].

\section{$\mathrm{Na}^{+}$and $\mathrm{Ca}^{2+}$ bind to site 2 in distinct manners}

In the crystal structure of $\mathrm{Na}_{\mathrm{v}} \mathrm{Rh}, \mathrm{a} \mathrm{Ca}^{2+}$ ion is bound to a site coincident with the site 2 described above (Supplementary information, Figure S7A). To further characterize the nature of this binding site, we co-crystallized $\mathrm{Na}_{v} \mathrm{Rh}$ with heavy metal ions. Data sets of $\mathrm{Ba}^{2+}$ and $\mathrm{Rb}^{+}$ derivatives were collected at the resolution of $3.5 \AA$ and $3.75 \AA$ A, respectively (Supplementary information, Table $\mathrm{S} 2$ ). The strong anomalous signal by $\mathrm{Ba}^{2+}$ indicates its location at site 2 , as shown by the electron density contoured at $12 \sigma$ (Supplementary information, Figure S7B). Similarly, the monovalent $\mathrm{Rb}^{+}$ion is also located at the same position (Supplementary information, Figure S7C). The positioning information based on the identifiable anomalous X-ray signals provides direct evidence that site 2 possesses enough space to non-selectively accommodate a number of the alkali and alkaline earth metal ions, such as $\mathrm{Ca}^{2+}$, in an almost fully hydrated state. Therefore, we investigated the detailed interaction be-

Figure $2 \mathrm{Ca}^{2+}$ binds to site 1 and blocks $\mathrm{Na}^{+}$entry from the extracellular side. (A) Free energy estimated from the negative logarithm of ion density at site 1 is shown for $\mathrm{Na}^{+}$(orange) and $\mathrm{Ca}^{2+}$ (green), respectively, as a function of the axial position of SF. The approximate positions of Ser181 and Glu183 are labeled. (B) Numbers of coordinating atoms are indicated for $\mathrm{Na}^{+}$ (orange)/ $/ \mathrm{Ca}^{2+}$ (green) in left panel, or for $\mathrm{Na}^{+}$in the presence of $\mathrm{Ca}^{2+}$ bound at site 1 (blue) in right panel. The total coordination numbers and the contribution from water molecules are shown as dashed and solid lines, respectively. (C) Coordination numbers contributed by Ser181 (solid line) or Glu183 (dashed line) are indicated in the same scheme as in B. The data shown in A-C are derived from simulations 1, 3 and 10, respectively. (D) The simulated structures of $\mathrm{SF}$ when $\mathrm{Na}^{+}$or $\mathrm{Ca}^{2+}$ binds to site $1 . \mathrm{Na}^{+}$(brown sphere) bound to Glu183 and Ser181 (upper left panel), Ser181 (upper right panel), and Ca ${ }^{2+}$ (green) bound to Glu183 (lower left panel) are shown. $\mathrm{Na}^{+}$is stably coordinated by Glu183 and Ser181 when $\mathrm{Ca}^{2+}$ is bound to Glu183 in the non-adjacent protomer (lower right panel). The subunits of $\mathrm{Na}_{\mathrm{v}} \mathrm{Rh}$ are shown in four colors to highlight the intrinsic asymmetry. The same color scheme is applied to all the figures if not otherwise indicated. (E) The 2D free energy estimated from radial-axial density in SF is plotted for $\mathrm{Na}^{+}$(upper panel) and $\mathrm{Ca}^{2+}$ (lower panel) in unit of kcal/mol. Ser181 and Glu183 are labeled along the SF axis. (F) PMF values of $\mathrm{Na}^{+}$(red) and $\mathrm{Ca}^{2+}$ (green) as a function of the SF axis illustrate that Ca ${ }^{2+}$ has to overcome a huge energy barrier to reach site 2 . 


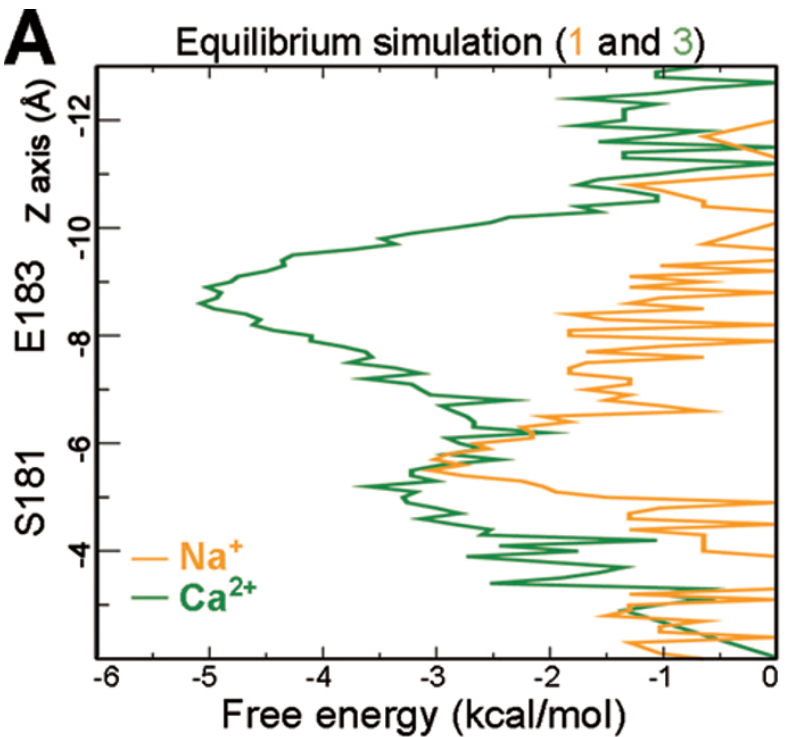

D
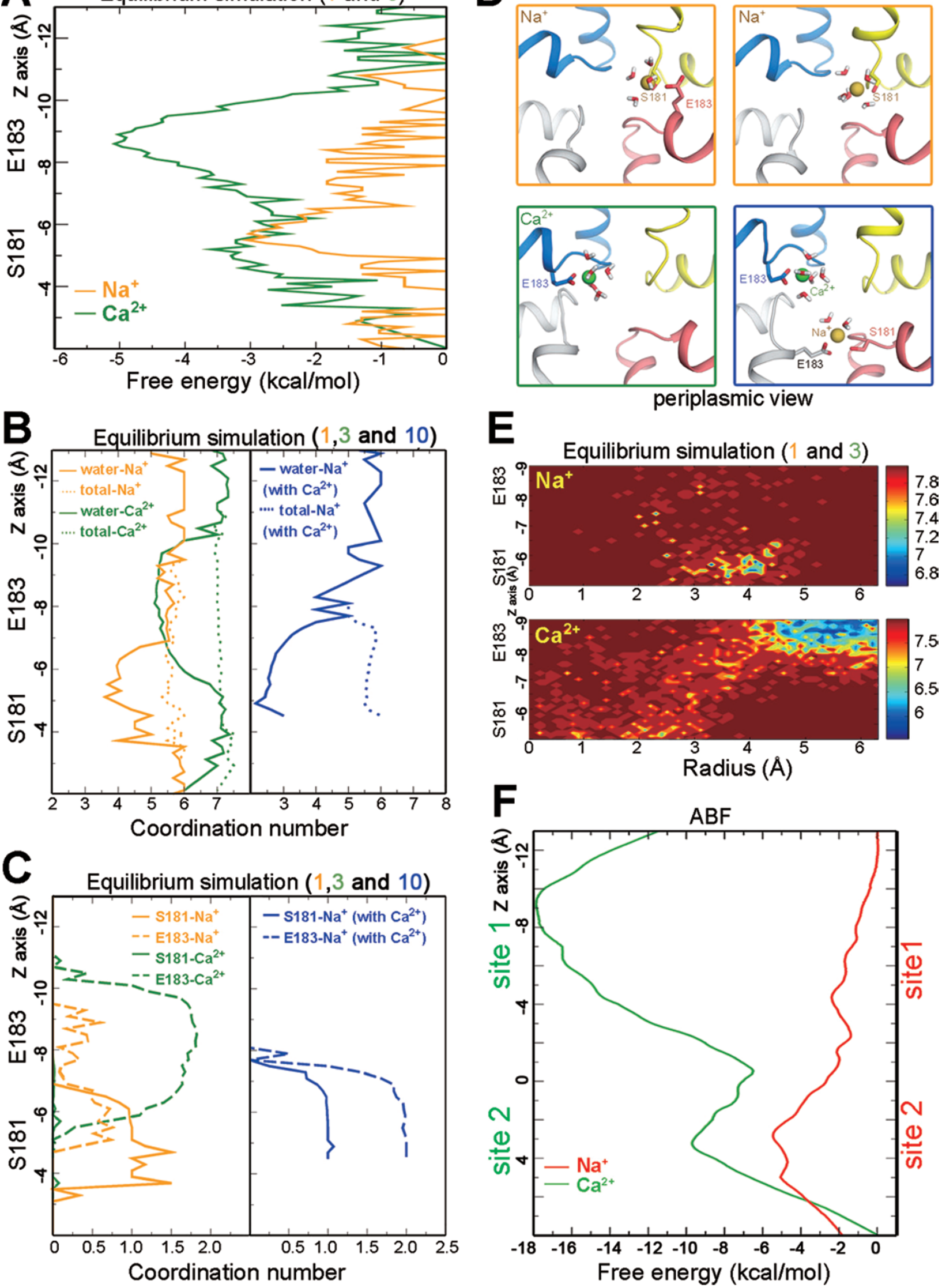

Cell Research | Vol 23 No 3 | March 2013 
tween $\mathrm{Ca}^{2+}$ and site 2 by conducting the simulation (simulation 8 in Supplementary information, Table S1) where a $\mathrm{Ca}^{2+}$ ion was initially restricted in the cavity beneath site 2 (Supplementary information, Movie S5).

Upon the removal of the restriction, $\mathrm{Ca}^{2+}$ enters $\mathrm{SF}$ immediately, occupies site 2 and is snugly bound there for the rest of the $30 \mathrm{~ns}$ trajectory (Figure 3A). Further analysis shows that $\mathrm{Na}^{+}$and $\mathrm{Ca}^{2+}$ lose 1.5 and 1 coordinated water molecule on average, respectively, in order to interact with the surrounding protein atoms (Figure 3B and Supplementary information, Figures S5C, S6B and $\mathrm{S} 6 \mathrm{D}) . \mathrm{Ca}^{2+}$ prefers to remain at the center of site 2, within similar distances to the eight carbonyl oxygen atoms surrounding the binding site, an observation consistent with the electron density seen in the crystal structure of $\mathrm{Na}_{\mathrm{v}} \mathrm{Rh}$. As a contrast, $\mathrm{Na}^{+}$lingers off the central axis by about 2-3 $\AA$ to randomly bind to one or two of the surrounding carbonyl oxygen atoms, and even to jump from one protomer to another frequently (Figure 3C, 3D and Supplementary information, Movie S1). This asymmetric positioning of $\mathrm{Na}^{+}$also causes larger asymmetrical conformational changes of the SF, compared to the central positioning of $\mathrm{Ca}^{2+}$ (Figure 3C and Supplementary information, Figure S8). Notably, both $\mathrm{Na}^{+}$and $\mathrm{Ca}^{2+}$ prefer close interaction with the carbonyl oxygen atoms from Leu179 at site 2 rather than Thr178 (Figure 3E and Supplementary information, Figure S5D).

Further electrophysiological characterization shows that antagonism of $\mathrm{Na}^{+}$current is substantially more potent when $\mathrm{Ca}^{2+}$ is applied from the intracellular side $\left(\mathrm{IC}_{50}\right.$ $\sim 61 \mu \mathrm{M}$, Figure $3 \mathrm{~F}$ ) compared to that of the extracellular side $\left(\mathrm{IC}_{50} \sim 10 \mathrm{mM}\right.$ [37]) in HEK-293T cells expressing the $\mathrm{NaChBac} / \mathrm{Na}_{v} \mathrm{Rh}$-filter chimera channels, as well as
$\mathrm{NaChBac}$ and $\mathrm{hNa}_{\mathrm{v}} 1.1$.

\section{$\mathrm{Na}_{\mathrm{v}} \mathrm{Rh}$ translocates $\mathrm{Na}^{+}$in an asymmetric manner}

In the crystal structure of $\mathrm{Na}_{\mathrm{v}} \mathrm{Rh}$, the conformations of the functional groups in SF from four subunits are not identical, and the negatively charged SF vestibule adopts an asymmetric tetramer (Supplementary information, Figure S9A). When passing through the SF, the partially dehydrated $\mathrm{Na}^{+}$preferentially binds to one or two oxygen atoms from residues in SF to preserve its intact coordination shell. In order to do this, $\mathrm{Na}^{+}$has to move up to $5 \AA$ off the central axis of the permeation pathway. $\mathrm{Na}^{+}$bound at site 1 or site 2 both display this asymmetric property (Figure 4A and Supplementary information, Figure S9B). In addition, the SF itself also experiences asymmetrical structural changes accompanying the permeation event. The conformation of the groups involved in ion coordination shows significant structural heterogeneity after superposition on the pore domain (Figure 4B and Supplementary information, Figure S8A).

One of the most significant evolutionary adaptations from bacterial sodium channels to mammalian orthologs is the divergent variations in the primary sequences of the four repeats. Unexpectedly, the four chemically identical subunits in $\mathrm{Na}_{\mathrm{v}} \mathrm{Rh}$ exhibit distinct structures and play nonequivalent roles during the permeation of each $\mathrm{Na}^{+}$ion. As seen in simulation 1 in Supplementary information, Table S1, only the side groups of Ser181 in one protomer (yellow) and Glu183 from the adjacent one (red) are directly involved in $\mathrm{Na}^{+}$binding at site 1 (Figure 2D and Supplementary information, Movie S1). The two adjacent protomers participating in $\mathrm{Na}^{+}$binding are stochastically selected by the incoming ion since the four

Figure $3 \mathrm{Na}^{+}$and $\mathrm{Ca}^{2+}$ bind to site 2 differently. (A) $\mathrm{Ca}^{2+}$ coming from intracellular side stays at site 2 but cannot penetrate into the extracellular solution. Free energy estimated from the negative logarithm of ion density at site 2 as a function of the axial position of SF is indicated for $\mathrm{Na}^{+}$(orange) and $\mathrm{Ca}^{2+}$ (green). The approximate positions of carbonyl oxygen atoms (O) of Thr178 and Leu179 are labeled. (B) Numbers of coordinating atoms are shown for $\mathrm{Na}^{+}$(orange) and Ca ${ }^{2+}$ (green). The

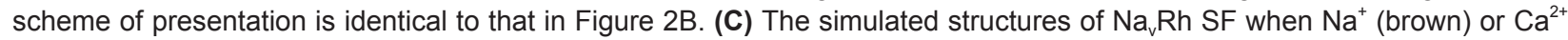
(green) binds at site 2. Two perpendicular views are shown. The distances between the ions and the surrounding carbonyl oxygens are indicated in dashed line and labeled in the unit of $\AA$. (D) The 2D free energies estimated from the negative logarithm of ion density in the SF are plotted for $\mathrm{Na}^{+}$(upper panel) and $\mathrm{Ca}^{2+}$ (lower panel) in unit of kcal/mol. Thr178 and Leu179 are labeled along the SF axis. (E) Coordination numbers contributed by Thr178 (O) or Leu179 (O) are indicated in dashed and solid lines, respectively, in the same color scheme as $\mathbf{B}$. The data of $\mathbf{B}$ and $\mathbf{E}$ are derived from ABF simulation (left panel) and equilibrium simulations 1 and 8 (right panel), respectively. (F) Cytosolic $\mathrm{Ca}^{2+}$ ions block $\mathrm{Na}^{+}$ion conductance through the channel pore. The relationship between average normalized current density from cells expressing the NaChBac (black traces), the $\mathrm{NaChBac} / \mathrm{Na}_{\mathrm{v}} \mathrm{Rh}$-filter chimera (green traces) and human $\mathrm{Na}_{\mathrm{v}} 1.1$ (purple traces) channels are plotted as a function of intracellular free calcium concentration ( \pm SEM; $n=5$ to 6 cells each) and are fit to the Hill equation. The estimated $\mathrm{IC}_{50}$ values are $74 \mu \mathrm{M}, 61 \mu \mathrm{M}$ and $98 \mu \mathrm{M}$ for $\mathrm{NaChBac}$, the $\mathrm{NaChBac} / \mathrm{Na}_{\mathrm{v}} \mathrm{Rh}$-filter chimera and $\mathrm{hNa} \mathrm{v}_{\mathrm{v}} 1.1$, respectively. Inset: representative inward $\mathrm{Na}^{+}$current density records from whole cell patches of HEK-293T cells expressing sodium channels in the presence of the indicated intracellular free calcium concentrations. Channels were activated by $0.5 \mathrm{~s}$ or $0.05 \mathrm{~s}\left(\mathrm{hNa} \mathrm{v}_{\mathrm{v}} 1.1\right)$ depolarizations from $-140 \mathrm{mV}$ (holding potential) to $0 \mathrm{mV}$ with $150 \mathrm{mM} \mathrm{NaCl}$ in the bath. 

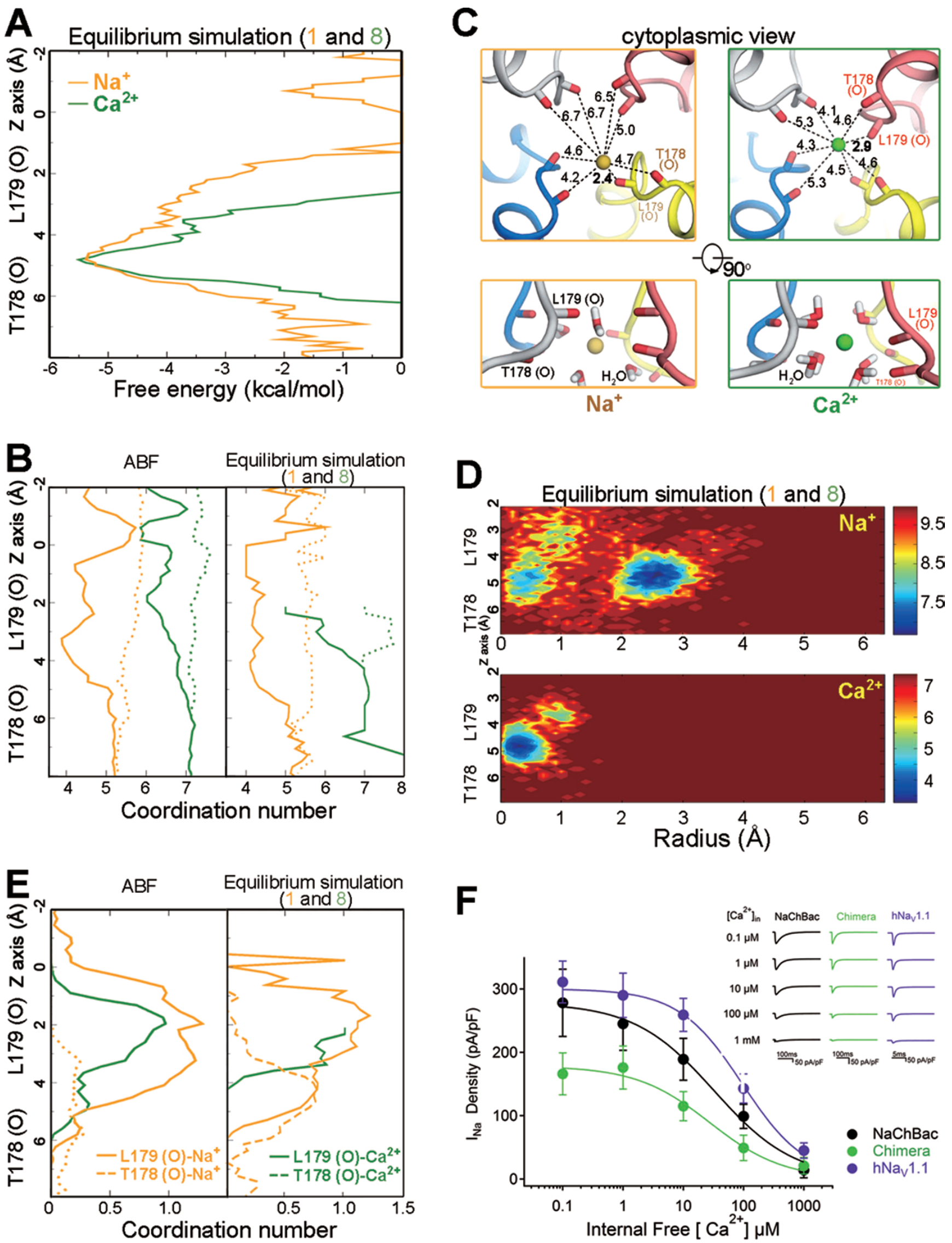
A

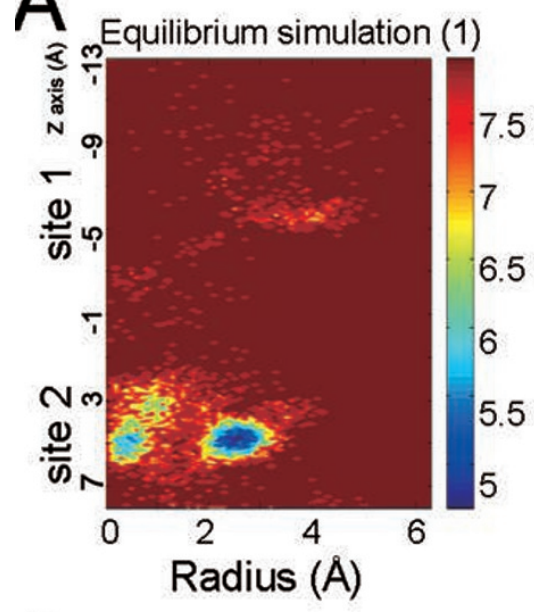

B
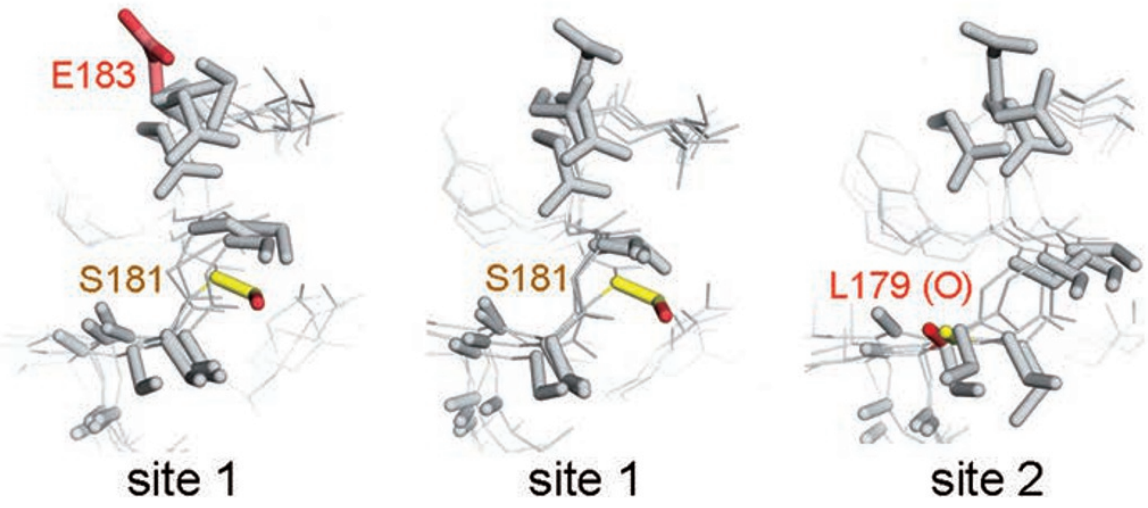

C

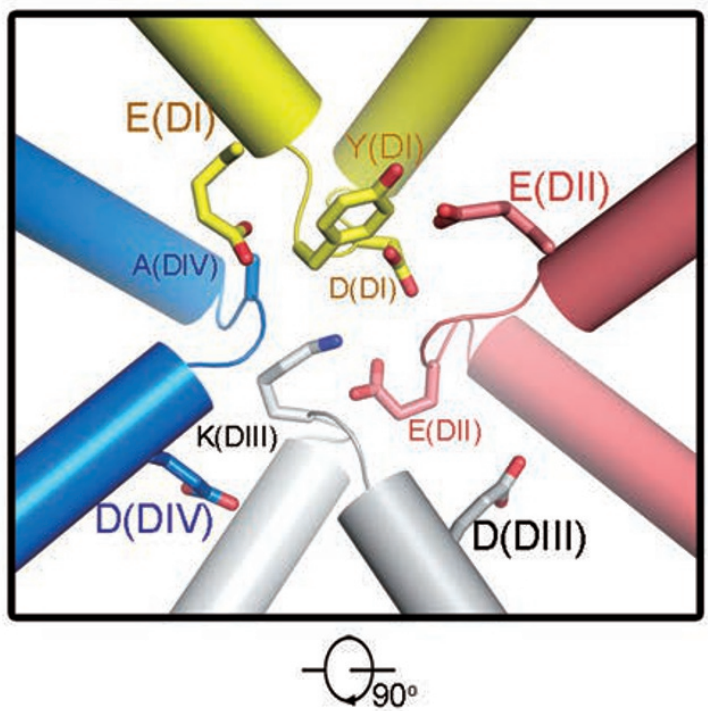

D
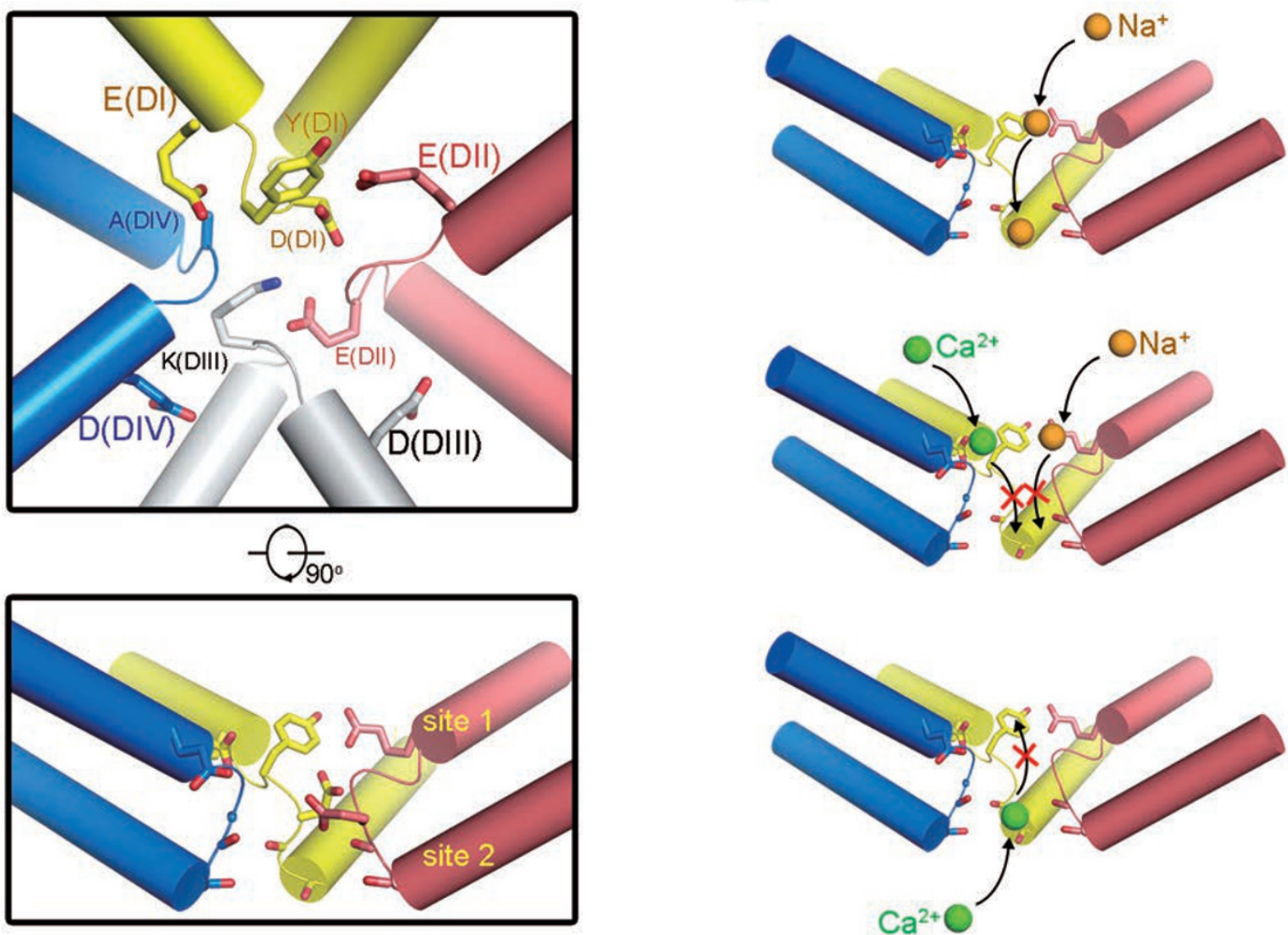

Figure $4 \mathrm{Na}^{+}$passes through the vestibule of $\mathrm{Na}_{\mathrm{v}} \mathrm{Rh} \mathrm{SF}$ in an asymmetric manner. (A) The 2D free energy estimated from the negative logarithm of radial-axial densities of $\mathrm{Na}^{+}$in the whole SF. (B) Superposition of the four protomers of the pore domain in the representative simulated structures when a $\mathrm{Na}^{+}$binds to site 1 (left and middle panels) or site 2 (right panel). The groups involved in $\mathrm{Na}^{+}$binding are highlighted in colored sticks. (C) Schematic representation of modeled mammalian $\mathrm{Na}_{v}$ channel structure in two perpendicular views. The outer negatively charged ring and Tyr constitute site 1 . The conserved residues DEKA from the four domains form the inner ring beneath site 1. Site 2 consists of eight carbonyl oxygen atoms. (D) The simulation-derived mechanisms by which $\mathrm{Na}_{v}$ channels discriminate $\mathrm{Na}^{+}$and $\mathrm{Ca}^{2+}$ as well as the block of $\mathrm{Na}^{+}$permeation by $\mathrm{Ca}^{2+}$. An $\mathrm{Na}^{+}$ion enters SF and binds to site 1 and site 2 sequentially; a $\mathrm{Ca}^{2+}$ ion can be well coordinated at site 1 when entering from extracellular side, or at site 2 when coming from intracellular side. The transfer of $\mathrm{Ca}^{2+}$ between the two sites is suppressed by a high-energy barrier. 
subunits have identical primary sequences. $\mathrm{Na}^{+}$binding becomes less random in mammalian $\mathrm{Na}_{\mathrm{v}}$ channels, where counterparts of Ser181 in the four domains are Y-GG, respectively, and Tyr is the only candidate capable of offering a hydroxyl group. Therefore, $\mathrm{Na}^{+}$is expected to bind to the site composed of Tyr in Domain I and a negatively charged residue in the adjacent domain. When $\mathrm{Na}^{+}$ crosses the inner ring composed of DEKA, it encounters the similar energy barrier as the one formed by Ser 180 in $\mathrm{Na}_{\mathrm{v}} \mathrm{Rh}$ (Figure $4 \mathrm{C}$ ). The innermost binding site (site 2) in mammalian channel may also bind to $\mathrm{Na}^{+}$and $\mathrm{Ca}^{2+}$ in distinct ways as in $\mathrm{Na}_{\mathrm{v}} \mathrm{Rh}$.

$\mathrm{Na}^{+}$permeation may follow the same knock-on mechanism for mammalian channels based on our simulation: $\mathrm{Na}^{+}$from the extracellular side binds to two sites in mammalian $\mathrm{Na}_{\mathrm{v}}$ channel sequentially, and then leaves for the cavity. The current will be blocked by a $\mathrm{Ca}^{2+}$ ion bound at site 1 . If a $\mathrm{Ca}^{2+}$ ion enters site 2 from the cytoplasmic side, it can also block the $\mathrm{Na}^{+}$current by sitting in the center of eight carbonyl oxygens (Figure 4D). This model is consistent with published experimental evidence $[29-33,37]$.

\section{Discussion}

\section{The role of Ser180 in ion permeation}

To transfer from site 1 to site $2, \mathrm{Na}^{+}$has to pass through the constriction site surrounded by the side chain of Ser180, a residue equivalent, as in the primary sequence, to the selectivity-determining key residues DEKA in mammalian $\mathrm{Na}_{\mathrm{v}}$ channels (Figure 1A). Location of Ser180 coincides with the free energy barrier in the permeation pathway (Figure 1D, right panel). Both clues imply that Ser180 may play an essential role in the selectivity of $\mathrm{Na}^{+}$.

In simulations 1 and 2, Ser 180 picks up $\mathrm{Na}^{+}$from Ser181 in site 1 and transfers it to site 2 (Supplementary information, Figure S10A). This phenomenon can be interpreted by the $2 \mathrm{D}$ free energy plot created from the negative logarithm of ion residence probability (Supplementary information, Figure S10B, left panel). Notably, three energy local minima (clusters 1, 2 and 3 in the right panel of Supplementary information, Figure S10B) can be identified on the 2D map of $\mathrm{Na}^{+}$, which constitute a consecutive transition pathway. More specifically, as $\mathrm{Na}^{+}$ departs from Ser181 in site 1, it first leaves the central axis and randomly interacts with the side chain of Ser 180 from one protomer. With deeper penetration, it transiently recovers the fully hydrated state and moves back to the center, before its final capture by the carbonyl oxygen of Leu179 at site 2 (Supplementary information, Figure S10C, left and middle panels).
Despite its low permeability through $\mathrm{Na}_{\mathrm{v}} \mathrm{Rh}, \mathrm{Ca}^{2+}$ was observed to go through the SF in the presence of $200 \mathrm{mM}$ $\mathrm{CaCl}_{2}$ with low probability (simulation 5 in Supplementary information, Table S1 and Movie S3). During this process, $\mathrm{Ca}^{2+}$ stays along the central axis (Supplementary information, Figure S10B, right panel), and hardly has direct interaction with the hydroxyl group of Ser180 (Supplementary information, Figure S10C, right panel). Occasionally, $\mathrm{Ca}^{2+}$ coordinates the backbone carbonyl oxygen of Ser180, when the backbone of this residue is flipped after an energetically costly conformational change (Supplementary information, Figure S10D).

Combining the simulations of $\mathrm{Na}^{+}$and $\mathrm{Ca}^{2+}$, Ser180 may play an essential role in reducing the energy barrier of $\mathrm{Na}^{+}$permeation, as compared to $\mathrm{Ca}^{2+}$ permeation. This proposed role is awaiting the further validation by mutational experiments.

\section{Implication on the eukaryotic sodium and calcium chan- nels}

Compared to other $\mathrm{NaChBac}$ orthologs, $\mathrm{Na}_{\mathrm{v}} \mathrm{Rh}$ contains an SF sequence more similar to that of mammalian $\mathrm{Na}_{\mathrm{v}}$ channels. Study of the $\mathrm{Na}_{\mathrm{v}} \mathrm{Rh} \mathrm{SF}$, thereby, reveals novel insights into the mechanism of $\mathrm{Na}^{+}$selectivity. The simulation studies show that $\mathrm{Na}_{\mathrm{v}} \mathrm{Rh}$ allows $\mathrm{Na}^{+}$permeation in an asymmetric manner, with the four chemically identical subunits following independent structural changes. This manner may also be adopted by its mammalian counterpart, whose four repeats contain varied sequences at SF. During permeation, $\mathrm{Na}^{+}$is more likely to bind to hydroxyl groups. $\mathrm{Ca}^{2+}$, on the other hand, prefers the more electronegative carboxylate groups (Figure 2C and Supplementary information, Figure S10C). In $\mathrm{Ca}_{\mathrm{v}}$ channels, the negatively charged outer ring is replaced by some polar residues, such as TNPQ in $\mathrm{hCa}_{\mathrm{v}} 1.3$ (Figure 1B). Therefore, the free energy well near site 1 is expected to become shallower during $\mathrm{Ca}^{2+}$ permeation. Simultaneously, $\mathrm{Ca}^{2+}$ channels have four Glu residues at the position corresponding to Ser180 in $\mathrm{Na}_{\mathrm{v}} \mathrm{Rh}$. These residues are proposed to attract $\mathrm{Ca}^{2+}$ more favorably than the outer binding site. If we assume that the four Glu form the second binding site, $\mathrm{Ca}^{2+}$ is likely to follow the same permeation pattern as $\mathrm{Na}^{+}$in $\mathrm{Na}_{\mathrm{v}} \mathrm{Rh}$, by naturally moving from the less favorable outer binding site to the more favorable inner binding site spontaneously. The binding of an incoming ion on the vacant outer site will partially destabilize the ion at the inner site and further approaching of the extracellular ions will trigger the sequential ion diffusion toward the cytoplasm. Although the mechanisms of eukaryotic $\mathrm{Na}^{+}$and $\mathrm{Ca}^{2+}$ channels may be predicted from our study on the bacterial sodium channel, a more convincing illustration requires the 
atomic structures of eukaryotic $\mathrm{Na}_{\mathrm{v}}$ and $\mathrm{Ca}_{\mathrm{v}}$ channels.

\section{Limitation of simulation}

The work in this paper was principally explored by MD simulations, although co-crystallization and electrophysiological experiments were conducted to facilitate the argument justification. There are limitations in our MD simulations. First, the non-polarizable force field was adopted here to accelerate computation, which may introduce errors since the non-negligible charge transfer from protein to the bound cation is omitted in non-polarizable force field [49]. Second, the current CHARMM force field cannot perfectly reproduce the solvation energy of $\mathrm{Ca}^{2+}$ ions. To fairly compare the binding behaviors between $\mathrm{Na}^{+}$and $\mathrm{Ca}^{2+}$, NB-fix parameters for $\mathrm{Na}^{+}$ions were not employed. Therefore, the force field parameters used in this work have deficiencies in evaluating the hydration of cations. Third, the cell membrane, which is composed of various lipid species, was oversimplified by POPC lipid bilayers in our simulation. Finally, the crystal structure of $\mathrm{Na}_{\mathrm{v}} \mathrm{Rh}$, which provides the basis for the simulation studies here, was captured in an inactivated conformation [37] in that both the extracellular mouth of SF and the cytoplasmic gate of pore domain are closed while all the gating charges in VSDs are exposed to the extracellular side. When the pore domain structure was adopted to perform the in silico studies, the cytoplasmic gate keeps closed in all simulations. Therefore in the simulations, the $\mathrm{Na}^{+}$ions only penetrate through the SF vestibule and dwell at site 2 , but no longer go further. A crystal structure of the pore domain with open inner gate is required to complete the simulation of ion permeation across the pore.

Despite the above limitations, as the first computational study on $\mathrm{Na}_{\mathrm{v}} \mathrm{Rh}$, our research rationalizes the mechanism by which the channel selectively conducts $\mathrm{Na}^{+}$ against $\mathrm{Ca}^{2+}$, and suggests the asymmetrical permeation manner of $\mathrm{Na}^{+}$in $\mathrm{Na}_{\mathrm{v}} \mathrm{Rh}$ and possibly in its eukaryotic counterparts. The conclusions presented here still await further validation by simulations using more advanced force field and by biochemical and electrophysiological experiments.

\section{Materials and Methods}

\section{Model definition}

Atomic coordinates of $\mathrm{Na}_{\mathrm{v}} \mathrm{Rh}$ channel were taken from the Protein Data Bank (code: 4DXW), and only the pore domain of the channel (residue 118-228 in all chains) was preserved for MD simulation. Before simulation, the protein was oriented along the $\mathrm{z}$ axis, was inserted into a pre-equilibrated POPC lipid bilayer (containing 187 POPC molecules) by aligning the geometrical center of the transmembrane residues of the protein against the center of the bilayer, and then was solvated by about 16000 TIP3P water molecules after removing all lipid molecules having steric confliction with the inserted protein. The system was electrostatically neutralized by the salt $\mathrm{XCl}$, where $\mathrm{X}$ corresponds to $\mathrm{Na}^{+}, \mathrm{Ca}^{2+}$ or their combination (see Supplementary information, Table S1 for detailed information). All simulations were performed by NAMD 2.8 [50] in an NPT ensemble, using CHARMM27 force field with CMAP correction [51]. The pressure was held at $1 \mathrm{~atm}$ by the Nose-Hoover Langevin piston $[52,53]$ and the temperature was controlled at $310 \mathrm{~K}$ by the Langevin thermostat [53]. The van der Waals interaction was smoothly switched to zero from $10 \AA$ to $12 \AA$, and all interations beyond $12 \AA$ were ignored from energy calculation. The electrostatic potential was solved using the particle mesh Ewald [54] method with periodic boundary conditions applied in all directions.

\section{The equilibrium simulation}

The system was preequilibrated in three successive steps (each lasting $0.5 \mathrm{~ns}$ ): (1) all atoms except those belonging to the lipid tails were fixed in the first stage to relax the lipid-protein interaction; (2) protein atoms were harmonically restrained with a force constant of $5 \mathrm{kcal} / \mathrm{mol} / \AA^{2}$ to relax the protein-water interaction; (3) all atoms are allowed to move freely. After the 1.5 -ns prequilibration, the protein has been well accomodated within the lipid membrane, as shown by the stable protein structure and system energy in Supplementary information, Figures S11 and S12, respectively. The productive simulation was then run for 50 ns using an integration time step of $2 \mathrm{fs}$, where the hydrogen atoms were restrained by the SETTLE algorithm [55], and the area of membrane was held constant. In all numerical analysis upon the trajectory, the first 5 ns were removed from the trajectory, to guarantee the sufficient equilibration of the system before analysis. In total, 15 equilibrium simulations were conducted and their details were shown in Supplementary information, Table S1.

\section{The adaptive biasing force simulation}

PMF was calculated using the ABF method [42-45]. Distance between the target ion and the geometric center of all $\alpha$-carbons in the SF (residue 178 to 183 ) projected on the axis perpendicular to the membrane was chosen as the reaction coordinate, which was further divided into six non-overlapping windows with the most extracellular one spanning $6 \AA$ and the others $3 \AA$. In the two most extracellular windows (win 0 and win1), the target ion was forbidden to move $6 \AA$ away from the central axis of the permeation pathway. The initial structure was extracted from snapshot at 5.8 $\mathrm{ns}$ in the equilibrium simulation in $\mathrm{NaCl}$. The system was then minimized and equilibrated for $2 \mathrm{~ns}$. The integration time step was chosen as $1 \mathrm{fs}$ and all other parameters were kept identical to the equilibrium simulation. The calcium system was built from the sodium system by replacing two randomly chosen sodium ions with one calcium ion in order to maintain the electrostatic neutrality. The system was then minimized and equilibrated for $2 \mathrm{~ns}$. To generate initial configurations for each $\mathrm{ABF}$ window, the ions were pulled through the permeation pathway with a constant velocity of $10 \AA / n s$, using the Steered Molecular Dynamics (SMD) [56]. Snapshots from the SMD trajectory were manually chosen as the initial coordinates for the six ABF windows, respectively, after 2 ns additional equilibration. A force of $100 \mathrm{kcal} / \mathrm{mol} / \AA \AA$ was applied to restrain the ion in each window, and the PMF was calculated se- 
quentially with the stepsize of $0.05 \AA$. In each step, 5000 samples were collected to roughly estimate the biasing force, and PMF was then updated every 2 ns and the calculation was conducted until two sequentially updated PMF curves differ by $<0.5 \mathrm{kcal} /$ mol. Finally, PMF curves obtained from different windows were spliced together by running a short simulation through the reaction coordinate. The overall simulation time therefore exceeded $154 \mathrm{~ns}$ and $190 \mathrm{~ns}$ in the sodium and calcium system, respectively.

\section{FEP method}

The binding free energy was estimated using the FEP [46, 47] method, following the scheme shown in Supplementary information, Figure S13. In particular, the relative binding free energy corresponds to the difference between annihilation free energies of the target ion bound at the site and the ion in water. For simplification, this energy difference was calculated in one process, in which the target ion vanished in the binding site and another ion appeared in the bulk water simultaneously. The inconsistancy in system size is avoided by this concurrent alchemical transformation scheme. At the beginning, a structure with an ion bound at the site was manually taken from the ABF trajectory and then was equilibrated for 1 ns. The ion was harmonically restrained in the binding site during equilibration and FEP calculation. As in the ABF calculation, the target ion was penalized to move away from the central axis of the permeation pathway in order to prevent the overlap of the ion and protein atoms. In details, the ion is allowed to move freely within $3.3 \AA$ away from the permeation axis and within $0.1 \AA$ along the permeation pathway. Once the ion left the allowed region, a force constant of $100 \mathrm{kcal} / \mathrm{mol} / \AA^{2}$ was applied to pull the ion back. The $\mathrm{Na}^{+}$in the bulk region was chosen as the reference state. The reference $\mathrm{Na}^{+}$was sufficiently far $(12 \AA)$ away from the protein, however, sharing the same positional restraint (within $3.3 \AA$ away from the permeation axis and within $0.1 \AA$ along the permeation pathway) as the target ion. Therefore, the calculated values were not absolute binding free energies. To derive the latter, correction on the translational entropy loss due to positional restraints should be added, which equals to $-k_{B} T \cdot \ln \left(\mathrm{C}^{0} \Delta \mathrm{V}\right)$, where $k_{B}$ is the Boltzmann constant, $T$ is the temperature, $\mathrm{C}^{0}$ is the number density of the solute in $1 \mathrm{M}$ solution, and $\Delta \mathrm{V}$ is the volume of allowed space in positional restraint. The correction in this case is about 3.810 $\mathrm{kcal} / \mathrm{mol}$. All other parameters are the same as the ones taken in equilibrium simulation and intra-molecular interactions are decoupled from the FEP calculation. In all FEP calculations, the reaction coordinate was sufficiently stratified into 200 windows (Supplementary information, Table S4). In each window, the free energy calculation cost at least 30000 simulation steps, among which the first 4000 steps were used for preequlibration. The detailed numbers of steps for all windows are also listed in Supplementary information, Table S4. To guarantee the convergence, simulation in each window was conducted in both the forward and the backward directions until the probability distribution of energy changes in both directions, $P\left(\Delta E_{\text {forward }}\right)$ and $P\left(-\Delta E_{\text {backward }}\right)$, nearly completely overlap. After the $>12 \mathrm{~ns}$ simulation, the free energies calculated from the forward and the backward processes differ by $<1.5 \mathrm{kcal} /$ mol. Finally, Bennett acceptance ratio (BAR) estimator [57-59] was adopted to reliably estimate the mean and standard error of free energy changes by combining the forward and backward calculations. The BAR estimation was conducted using the parseFEP plugin of the VMD package [59].

\section{Hydration analysis}

All analysis on the hydration status of ions was performed using VMD. The radial distribution function $g(r)$ was calculated using the plugin of "radial pair distribution function $g(r)$ " in VMD. Only oxygens within $5 \AA$ from the target ion were considered in the calculation. According to the radial distribution function, the first hydration layer is within $3 \AA$ of the ion (see Supplementary information, Figure S6). The coordination number was estimated by counting the number of oxygen atoms of water and various protein groups within $3 \AA$ of the target ion. The final curve was derived by averaging the coordination profiles over numerous frames in the trajectries.

\section{Protein purification and crystallization}

The $\mathrm{Na}_{\mathrm{v}} \mathrm{Rh}$ proteins for crystallization were purified as previously described [37]. Crystals were grown at $18^{\circ} \mathrm{C}$ by the hanging-drop vapor diffusion method. Barium derivatives were obtained under the crystallization condition containing 4.5\% PEG 8000 (v/v), 100 mM HEPES-NaOH, pH 7.0, $50 \mathrm{mM} \mathrm{BaCl}_{2}, 10 \%$ glycerol and $15 \%$ 1,4-Butandiol. The crystals appeared in 2 days, and grew to form $50 \mu \mathrm{m} \times 50 \mu \mathrm{m} \times 100 \mu \mathrm{m}$ tetragonal rods in 5 days. Then the crystals were optimized through a dehydration manipulation by gradually increasing the precipitant concentration in $\mathrm{BaCl}_{2}$-containing buffer to 15\% PEG $400(\mathrm{v} / \mathrm{v}), 20 \%$ PEG 8000 $(\mathrm{v} / \mathrm{v})$. Rubidium derivatives were obtained in the same way as described above, except for $100 \mathrm{mM} \mathrm{RbCl}$ instead of $50 \mathrm{mM} \mathrm{BaCl}$ in the buffer.

\section{Data collection and structure refinement}

The diffraction data sets were collected at wavelengths of 1.54 $\AA$ and $0.81 \AA$ for $\mathrm{Ba}^{2+}$ and $\mathrm{Rb}^{+}$, respectively, at the Shanghai synchrotron radiation facility beamline BL17U. Both were integrated and scaled with HKL2000 [60]. The molecular replacement was carried out based on the native structure of $\mathrm{Na}_{\mathrm{v}} \mathrm{Rh}$ (PDB code: 4DXW) using programs from the CCP4 suite [61]. The structure was refined with PHENIX [62]. The anomalous difference maps were calculated using these data. Data collection statistics are summarized in Supplementary information, Table S2.

\section{Electrophysiology}

Whole-cell voltage-clamp experiments were performed at $22{ }^{\circ} \mathrm{C}$ on transiently transfected HEK-293 cells as described. Transfected cells were seeded onto glass coverslips and placed in a perfusion chamber for experiments where extracellular conditions could be exchanged. Unless otherwise stated, the extracellular solution contained $150 \mathrm{mM} \mathrm{NaCl}, 1.8 \mathrm{mM} \mathrm{CaCl}_{2}, 1 \mathrm{mM} \mathrm{MgCl}_{2}, 5 \mathrm{mM}$ glucose and $10 \mathrm{mM}$ HEPES, $\mathrm{pH}$ 7.4, and the intracellular (pipette) solution contained $105 \mathrm{mM}$ CsF, $5 \mathrm{mM}$ EGTA, $35 \mathrm{mM} \mathrm{NaCl}, 2 \mathrm{mM} \mathrm{Mg}$ and $10 \mathrm{mM}$ Hepes, $\mathrm{pH}$ 7.4. Calcium chloride was titrated into the intracellular solution to achieve free calcium concentrations of 0.1 M-1 mM. The MaxChelator program was used to estimate the free $\mathrm{Ca}^{2+}$ concentrations [63]. The sodium channel current density was measured by dividing the maximum inward current divided by the whole cell capacitance $(9-15 \mathrm{pF})$. The half maximal inhibitory concentration $\left(\mathrm{IC}_{50}\right)$ for the antagonism of sodium current was estimated by fitting the inward sodium current density for free $\mathrm{Ca}^{2+}$ concentration to the Hill Equation: current density $=1 /\left\{\left(\left[\mathrm{Ca}^{2+}\right] /\right.\right.$ $\left.\left.\mathrm{EC}_{50}\right)^{n}+1\right\}$, where $n$ is the Hill coefficient and $\left[\mathrm{Ca}^{2+}\right]$ is the estimated free calcium concentration. 


\section{Acknowledgments}

This work was supported by funds from the Ministry of Science and Technology of China (2011CB911102, 2011CB910501 and 2009CB918802), the National Natural Science Foundation of China (31125009 and 91017011) and Tsinghua University. The computational work was also supported by the Tsinghua National Laboratory for Information Science and Technology.

\section{References}

1 Hodgkin AL, Huxley AF. Resting and action potentials in single nerve fibres. J Physiol 1945; 104:176-195.

2 Hille B. Ion Channels of Excitable Membranes. 3rd Edition. Sunderland, MA: Sinauer Associates, 2001.

3 Guy HR, Seetharamulu P. Molecular model of the action potential sodium channel. Proc Natl Acad Sci USA 1986; 83:508-512.

4 Jiang YX, Lee A, Chen JY, et al. X-ray structure of a voltagedependent K+ channel. Nature 2003; 423:33-41.

5 Long SB, Campbell EB, Mackinnon R. Crystal structure of a mammalian voltage-dependent Shaker family $\mathrm{K}+$ channel. Science 2005; 309:897-903.

6 Long SB, Tao X, Campbell EB, MacKinnon R. Atomic structure of a voltage-dependent $\mathrm{K}+$ channel in a lipid membrane-like environment. Nature 2007; 450:376-382.

7 Butterwick JA, MacKinnon R. Solution structure and phospholipid interactions of the isolated voltage-sensor domain from KvAP. J Mol Biol 2010; 403:591-606.

8 Long SB, Campbell EB, Mackinnon R. Voltage sensor of Kv1.2:structural basis of electromechanical coupling. Science 2005; 309:903-908.

9 Hodgkin AL, Huxley AF. A quantitative description of membrane current and its application to conduction and excitation in nerve. J Physiol 1952; 117:500-544.

10 Doyle DA, Cabral JM, Pfuetzner RA, et al. The structure of the potassium channel:Molecular basis of $\mathrm{K}+$ conduction and selectivity. Science 1998; 280:69-77.

11 Zhou YF, Morais-Cabral JH, Kaufman A, MacKinnon R. Chemistry of ion coordination and hydration revealed by a $\mathrm{K}+$ channel-Fab complex at 2.0 angstrom resolution. Nature 2001; 414:43-48.

12 Nishida M, Cadene M, Chait BT, MacKinnon R. Crystal structure of a Kir3.1-prokaryotic Kir channel chimera. EMBO J 2007; 26:4005-4015.

13 Tao X, Avalos JL, Chen J, MacKinnon R. Crystal structure of the eukaryotic strong inward-rectifier $\mathrm{K}(+)$ channel Kir2.2 at 3.1 angstrom resolution. Science 2009; 326:1668-1674.

14 Hansen SB, Tao X, MacKinnon R. Structural basis of PIP(2) activation of the classical inward rectifier $\mathrm{K}(+)$ channel Kir2.2. Nature 2011; 477:495-498.

15 Whorton MR, MacKinnon R. Crystal structure of the mammalian GIRK2 $\mathrm{K}(+)$ channel and gating regulation by $\mathrm{G}$ proteins, PIP(2), and sodium. Cell 2011; 147:199-208.

16 Brohawn SG, del Marmol J, MacKinnon R. Crystal structure of the human K2P TRAAK, a lipid- and mechano-sensitive K+ ion channel. Science 2012; 335:436-441.

17 Clayton GM, Altieri S, Heginbotham L, Unger VM, Morais-
Cabral JH. Structure of the transmembrane regions of a bacterial cyclic nucleotide-regulated channel. Proc Natl Acad Sci USA 2008; 105:1511-1515.

18 Hille B. The permeability of the sodium channel to organic cations in myelinated nerve. J Gen Physiol 1971; 58:599-619.

19 Hille B. The hydration of sodium ions crossing the nerve membrane. Proc Natl Acad Sci USA 1971; 68:280-282.

20 Corry B, Thomas M. Mechanism of ion permeation and selectivity in a voltage gated sodium channel. J Am Chem Soc 2011; 134:1840-1846.

21 Furini S, Domene C. On conduction in a bacterial sodium channel. PLoS Comput Biol 2012; 8:e1002476.

22 McNulty MM, Edgerton GB, Shah RD, et al. Charge at the lidocaine binding site residue Phe-1759 affects permeation in human cardiac voltage-gated sodium channels. J Physiol 2007; 581:741-755.

23 Terlau H, Heinemann SH, Stuhmer W, et al. Mapping the site of block by tetrodotoxin and saxitoxin of sodium channel II. FEBS Lett 1991; 293:93-96.

24 Chiamvimonvat N, Perez-Garcia MT, Ranjan R, Marban E, Tomaselli GF. Depth asymmetries of the pore-lining segments of the $\mathrm{Na}+$ channel revealed by cysteine mutagenesis. Neuron 1996; 16:1037-1047.

25 Favre I, Moczydlowski E, Schild L. On the structural basis for ionic selectivity among $\mathrm{Na}+, \mathrm{K}+$, and $\mathrm{Ca} 2+$ in the voltagegated sodium channel. Biophys $J$ 1996; 71:3110-3125.

26 Schlief T, Schonherr R, Imoto K, Heinemann SH. Pore properties of rat brain II sodium channels mutated in the selectivity filter domain. Eur Biophys J 1996; 25:75-91.

27 Sun YM, Favre I, Schild L, Moczydlowski E. On the structural basis for size-selective permeation of organic cations through the voltage-gated sodium channel. Effect of alanine mutations at the DEKA locus on selectivity, inhibition by $\mathrm{Ca} 2+$ and $\mathrm{H}+$, and molecular sieving. J Gen Physiol 1997; 110:693-715.

28 Heinemann SH, Terlau H, Stuhmer W, Imoto K, Numa S. Calcium channel characteristics conferred on the sodium channel by single mutations. Nature 1992; 356:441-443.

29 Woodhull AM. Ionic blockage of sodium channels in nerve. $J$ Gen Physiol 1973; 61:687-708.

30 Armstrong CM, Cota G. Calcium ion as a cofactor in $\mathrm{Na}$ channel gating. Proc Natl Acad Sci USA 1991; 88:6528-6531.

31 Armstrong CM, Cota G. Calcium block of $\mathrm{Na}+$ channels and its effect on closing rate. Proc Natl Acad Sci USA 1999; 96:4154-4157.

32 Zamponi GW, French RJ. Sodium current inhibition by internal calcium:a combination of open-channel block and surface charge screening? J Membr Biol 1995; 147:1-6.

33 French RJ, Worley JF, Wonderlin WF, Kularatna AS, Krueger BK. Ion permeation, divalent ion block, and chemical modification of single sodium channels. Description by single- and double-occupancy rate-theory models. J Gen Physiol 1994; 103:447-470.

34 Ren D, Navarro B, Xu H, et al. A prokaryotic voltage-gated sodium channel. Science 2001; 294:2372-2375.

35 Yue L, Navarro B, Ren D, Ramos A, Clapham DE. The cation selectivity filter of the bacterial sodium channel, NaChBac. $J$ Gen Physiol 2002; 120:845-853.

36 Payandeh J, Scheuer T, Zheng N, Catterall WA. The crystal 
structure of a voltage-gated sodium channel. Nature 2011; 475:353-358.

37 Zhang X, Ren W, DeCaen P, et al. Crystal structure of an orthologue of the $\mathrm{NaChBac}$ voltage-gated sodium channel. Nature 2012; 486:130-134.

38 Carnevale V, Treptow W, Klein ML. Sodium ion binding sites and hydration in the lumen of a bacterial ion channel from molecular dynamics simulations. J Phys Chem Lett 2011; 2:2504-2508.

39 Qiu H, Shen R, Guo W. Ion solvation and structural stability in a sodium channel investigated by molecular dynamics calculations. Biochim Biophys Acta 2012; 1818:2529-2535.

40 Dudev T, Lim C. Factors governing the Na+ vs K+ selectivity in sodium ion channels. J Am Chem Soc 2010; 132:23212332.

41 Dudev T, Lim C. Why voltage-gated $\mathrm{Ca} 2+$ and bacterial $\mathrm{Na}+$ channels with the same EEEE motif in their selectivity filters confer opposite metal selectivity. Phys Chem Chem Phys 2012; 14:12451-12456.

42 Darve E, Pohorille A. Calculating free energies using average force. J Chem Phys 2001; 115:9169-9183.

43 Darve E, Rodriguez-Gomez D, Pohorille A. Adaptive biasing force method for scalar and vector free energy calculations. $J$ Chem Phys 2008; 128:144120.

44 Darve E, Wilson M, Pohorille A. Calculating free energies using a scaled-force molecular dynamics algorithm. Mol Simulat 2002; 28:113-144.

45 Rodriguez-Gomez D, Darve E, Pohorille A. Assessing the efficiency of free energy calculation methods. J Chem Phys 2004; 120:3563-3578.

46 Zwanzig RW. High-temperature equation of state by a perturbation method. II. Polar gases. J Chem Phys 1955; 23:19151922.

47 Kollman P. Free energy calculations: applications to chemical and biochemical phenomena. Chem Rev 1993; 93:2395-2417.

48 Hodgkin AL, Keynes RD. The potassium permeability of a giant nerve fibre. J Physiol 1955; 128:61-88.

49 Illingworth CJ, Domene C. Many-body effects and simulations of potassium channels. Proc R Soc A Mathem Phys Eng
Sci 2009; 465:1701-1716.

50 Phillips JC, Braun R, Wang W, et al. Scalable molecular dynamics with NAMD. J Comput Chem 2005; 26:1781-1802.

51 MacKerell AD Jr, Bashford D, Bellott M, et al. All-atom empirical potential for molecular modeling and dynamics studies of proteins. J Phys Chem B 1998; 102:3586-3616.

52 Martyna GJ, Tobias DJ, Klein ML. Constant pressure molecular dynamics algorithms. J Chem Phys 1994; 101:4177-4189.

53 Feller SE, Zhang Y, Pastor RW, Brooks BR. Constant pressure molecular dynamics simulation:the Langevin piston method. J Chem Phys 1995; 103:4613-4621.

54 Essmann U, Perera L, Berkowitz M, et al. A smooth particle mesh Ewald method. J Chem Phys 1995; 103:8577-8593.

55 Miyamoto S, Kollman P. Settle:an analytical version of the SHAKE and RATTLE algorithm for rigid water models. $J$ Comput Chem 1992; 13:952-962.

56 Izrailev S, Stepaniants S, Balsera M, Oono Y, Schulten K. Molecular dynamics study of unbinding of the avidin-biotin complex. Biophys J 1997; 72:1568-1581.

57 Bennett $\mathrm{CH}$. Efficient estimation of free energy differences from Monte Carlo data. J Comput Phys 1976; 22:245-268.

58 Pohorille A, Jarzynski C, Chipot C. Good practices in freeenergy calculations. J Phys Chem B 2010; 114:10235-10253.

59 Humphrey W, Dalke A, Schulten K. VMD: Visual molecular dynamics. J Mol Graph 1996; 14:33-38.

60 Otwinowski Z, Minor W. Processing of X-ray diffraction data collected in oscillation mode. Methods Enzymol 1997; 276:307-326.

61 The CCP4 suite: programs for protein crystallography. Acta Crystallogr D Biol Crystallogr 1994; 50:760-763.

62 Adams PD, Grosse-Kunstleve RW, Hung LW, et al. PHENIX: building new software for automated crystallographic structure determination. Acta Crystallogr D Biol Crystallogr 2002; 58:1948-1954.

63 Bers DM, Patton CW, Nuccitelli R. A practical guide to the preparation of Ca2+ buffers. Methods Cell Biol 1994; 40:329.

64 DeLano WL. The PyMOL Molecular Graphics System. 2002; http://www.pymol.org

(Supplementary information is linked to the online version of the paper on the Cell Research website.) 